\title{
Reseña del libro: \\ Territorios encarnados. Extractivismo, comunalismo y género en la Meseta P'urhépecha, de Verónica Velázquez. Premio Cátedra Jorge Alonso 2019. Universidad de Guadalajara y CIESAS. México.
}

Resenha: Territórios Encarnados. Extrativismo, comunalismo e gênero no platô de P'urhépecha, de Verónica Velázquez. Prêmio Jorge Alonso 2019, Universidade de Guadalajara e CIESAS. México.

Book Review: Incarnate Territories. Extractivism, communalism and gender in the P'urhépecha Plateau, by Verónica Velázquez. Jorge Alonso Award 2019, University of Guadalajara and CIESAS. Mexico.

\section{María Teresa Sierra ${ }^{1}$}

"Tras unos minutos llegó Irene del jornal de zarza, al entrar al cuarto donde yo contemplaba a su nieto le comenté con emoción: “iqué bonito bebe!, jes hermoso!”, y ella respondió en un tono algo llano "si verdad... estamos esperando a que se muera" esa frase de pronto detuvo todo a mí alrededor"(V. Velázquez, 2018:225)

Esta escena desgarradora con la que Verónica Velázquez describe un momento de encuentro con Irene, abuela de un bebé con hidrocefalia, de apenas dos meses de edad, en su trabajo de campo, revela de golpe los significados de una precariedad sistémica que marca la vida de mujeres jornaleras purépechas en Michoacán; actoras centrales de este libro. Estas frases me impactaron profundamente y las refiero porque me permiten poner en relevancia la sensibilidad etnográfica de la autora y su capacidad para referir en pocas palabras la crudeza de una realidad que atraviesa la vida de mujeres indígenas en territorios disputados por empresas transnacionales y el crimen organizado.

El libro "Territorios encarnados: Mujeres p'urhépechas ante el extractivismo agroindustrial y la autonomía de Cherán" es producto de su tiempo: retrata la dimensión humana y vivencial de procesos de gran complejidad y violencias múltiples que estructuran la vida de comunidades indígenas frente a nuevos ciclos de despojo en México y muy especialmente en la Meseta P'urhépecha. El lente analítico está puesto en las mujeres jornaleras que han visto transformadas sus vidas y la de sus familias ante procesos inéditos producto de una globalización neoliberal que las engulle, trastoca los órdenes de género y las sitúa en condiciones de riesgo e inseguridad incrementada; pero es también una ventana para abrir el horizonte de las resistencias comunitarias y las autonomías indígenas que en momentos límite han sido capaces de enfrentar los proyectos de muerte que se les imponen. En este sentido el libro es un referente de procesos similares que suceden en México y en otros países de América Latina.

Verónica Velázquez analiza el impacto de la transformación económica y social que se vive en comunidades de la meseta p'urhépecha debido al impacto del capital agroindustrial y la violencia criminal que lo acompaña afectando amplias extensiones de un territorio que ha cambiado radicalmente su fisonomía, acelerando procesos de desforestación y de reconversión económica en gran escala; se trata de comunidades, ahora colonizadas por la producción del aguacate y las frutillas de exportación. En especial aborda los efectos de estos procesos en la vida y cuerpos de mujeres jornaleras p'urhépechas provenientes de dos comunidades que comparten historias de larga duración y violencias estructurales pero que hoy en día están insertas en contextos distintos que hacen relevante su contraste: por un lado jornaleras de la comunidad de Santa Ana Zirosto - comunidad afectada por la erupción del Volcán Paricutín -, trabajadoras de la agroindustria de las berries de exportación y del aguacate cuyos horizontes de vida han cambiado radicalmente incrementando su precariedad y riesgos en la salud, y por otro lado jornaleras de la empresas comunales de San Francisco de Cherán -una comunidad que detuvo la deforestación y se confrontó al crimen organizado- que encuentran en el trabajo del jornal

${ }^{1}$ CIESAS-México. Correo electrónico: $\underline{\text { mtsierrac@hotmail.com }}$ 
nuevos sentidos de identidad y solidaridad comunal. El libro documenta el cúmulo de violencias que confluyen en la vida de las mujeres p'urhépechas así como la capacidad de agencia que pueden tener estas mujeres en espacios marcados por subordinaciones y exclusiones estructurales de género, clase y pertenencia étnica. De esta manera a partir de un trabajo con fuerte densidad etnográfica y una perspectiva histórica de los procesos que documenta, Verónica Velázquez construye un argumento de gran originalidad para comprender las consecuencias diversas de procesos similares en la vida laboral y cotidiana de mujeres p'urhépechas, lo que le da la oportunidad de reconstruir, por un lado, cómo el cúmulo de opresiones en unos casos contribuye a generar nuevas precariedades al enfrentarse al jornal agroindustrial y, por otro lado, de forma inversa cómo la inserción en un jornal comunitario ofrece la oportunidad de redefinir roles de género y abrir alternativas para las mujeres en un sentido colectivo e incluyente, como sucede en Cherán. Con el cuidado de no construir dicotomías ni de escencializar las identidades, Verónica Velázquez ubica a estas mujeres jornaleras considerando los retos que les toca enfrentar sin victimizarlas sino por el contrario mostrando la fuerza que las hace seguir adelante en contextos distintos y muchas veces riesgosos. Así con su trabajo la autora se adentra en dos realidades diferenciadas que nos ofrecen una ventana para analizar y comprender la heterogeneidad de procesos globales de gran complejidad y la agencia de las mujeres indígenas.

El libro revela la fuerza de la etnografía densa y su potencial para poner en primer plano las vidas humanas y sus dramas frente a violencias estructurales que están transformando aceleradamente a las comunidades indígenas y muy especialmente órdenes de género arraigados que antes se pensaban inamovibles; sin que ello signifique que se transformen las relaciones de poder que involucran y que afectan a las mujeres prioritariamente. Verónica da cuenta así de su capacidad para adentrarse en la subjetividad femenina, en un escenario devastador y contradictorio, y recuperar la mirada que construyen las mujeres jornaleras desde las vidas precarias que les toca vivir: las retrata así como mujeres de carne y hueso que al mismo tiempo que revelan sus sentires, angustias y dilemas cotidianos hacen ver también sus gustos y deseos. Es ahí donde la autora, siguiendo a Veena Dass (2008) y a Kimberly Theidon (2004), da cuenta de la condición humana de mujeres que construyen sus vidas en escenarios inciertos y con fuertes retos. La autora también se inspira exitosamente en trabajo de Judith Butler (2006) quién da cuenta de los efectos racializantes de la precarización de la vida que acompaña el despojo neoliberal y sus afectaciones en los cuerpos femeninos; pero Verónica va más allá al mostrar que las precariedades de "los cuerpos que no importan", siguiendo a Butler (op cit), en determinados contextos pueden activar una agencia social como parte de procesos colectivos de resistencia que ponen freno al capital y a los poderes fácticos, como lo revelan las mujeres de Cherán que con sus cuerpos pusieron un alto al despojo.

Un logro fundamental del libro es la perspectiva de contraste con la que consigue destacar los significados de la autonomía de Cherán y el protagonismo de las mujeres que han conseguido no sólo el reconocimiento de su comunidad sino sobre todo abrir grietas y sacudir anquilosados ordenes de género p'urhépechas; ello contrasta con los procesos de fragmentación, despojo, inseguridad y violencia que viven las mujeres jornaleras en regiones subordinadas a las lógicas del extractivismo agroindustrial y del crimen organizado, como es el caso de Zirosto. Así también es desde el contraste que cobran forma las modalidades diversas que asumen los comunalismos contemporáneos en la meseta purépecha como ejes transversales y renovados de la organización indígena que Verónica reconstruye en una perspectiva histórica y en vínculo con la defensa del territorio; con lo cual contribuye a la larga tradición de estudios sobre los procesos comunales en Michoacán.

En este sentido, la investigación que Verónica Velázquez presenta en este libro, resultado de un trabajo doctoral de largo aliento, revela un compromiso profundo por documentar las transformaciones aceleradas de la meseta p'urhépecha que han impactado su propia trayectoria de vida - ella misma mujer nacida en Uruapan donde la violencia se incrementó exponencialmente desde que el presidente Felipe Calderón inicio la guerra contra el narco desde el año 2006- haciendo evidente su posicionamiento político y su compromiso ético con las mujeres que acompañó en periodos diferenciados, lo que sin duda es uno de los distintivos de su libro y contribuirá a los debates actuales sobre el entendimiento de las violencias y las posibilidades de confrontarlas.

Por sus alcances analíticos y metodológicos y por atreverse a nombrar las violencias en sus dimensiones múltiples, documentarlas y mostrarlas en su crudeza, pero también por destacar la agencia de las mujeres indígenas y su capacidad de transformación social aún desde situaciones límites este libro 
constituye un aporte fundamental a la comprensión espacial y territorializada de las comunidades indígenas y sus transformaciones en el México de hoy.

Referencias bibliográficas

Butler, J. (2006). Fermín Rodríguez (trad.). Vida precaria: el poder del duelo y la violencia. Buenos Aires: Paidós.

Das, V. (2008). “La antropología de dolor". En Ortega, F. (ed.). Veena Das: Sujetos del dolor, agentes de dignidad. Bogotá: Universidad Nacional de Colombia Facultad de Ciencias Humanas, Instituto CES/ Universidad Nacional de Colombia sede Medellín/ Pontificia Universidad Javeriana, Instituto Pensar. pp. 409-436.

Theidon, K. (2004). Entre prójimos: el conflicto armado interno y la política de la reconciliación en el Perú. Perú: Instituto de Estudios Peruanos.

\section{PORTADA DEL LIBRO}

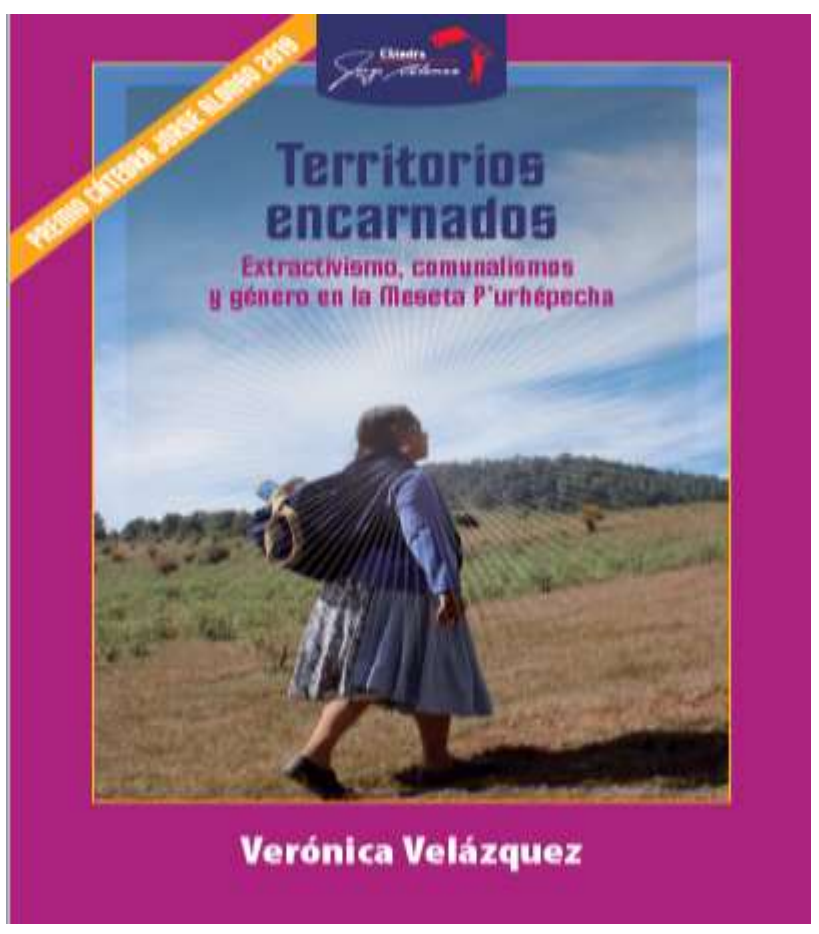

